\title{
Alternative Framework in "Body Coordination" Topic: A Progress Report for Interior of Malaysia
}

\author{
Davy Seligin ${ }^{1}$, Mohd. Zaki Ishak ${ }^{2}$, Jominin Goropos ${ }^{3}$ \\ ${ }^{1}$ School of Education and Cognitive of Science, Asia e-University, Malaysia \\ ${ }^{2}$ School of Education \& Social Development, University Malaysia Sabah, Malaysia \\ ${ }^{3}$ Sandakan East Sabah Malaysia College Community, Malaysia \\ Correspondence: Davy Seligin, School of Education and Cognitive of Science, Asia e-University, Malaysia
}

Received: October 20, 2014 Accepted: January 4, 2015 Online Published: March 24, 2015

doi:10.11114/jets.v3i3.562

URL: http://dx.doi.org/10.11114/jets.v3i3.562

\begin{abstract}
This preliminary study was conducted in interior of Malaysia. The study employed the Body Coordination Two Tier Concept Test to assess students' understandings of body coordination topic. The test consisted of 14 questions as two tier question style. The students needed to select the answer and write down the justifications of each answer. Interview was conducted with six students to get in-depth opinion about Body Coordination.
\end{abstract}

Keywords: alternative framework, misconception, body coordination

\section{Introduction}

Students came to school with various interpretations which may directly or indirectly contribute to understanding of Body Coordination (BC) topic. They cannot be considered as empty containers 'blank slates' which can be loaded by academic knowledge but they have rich experience, knowledge and their own beliefs about the phenomena that occur in nature (Zurida, Syarifah \& Mohd. Ali, 2006).

$\mathrm{BC}$ is part of the general science curriculum in upper secondary schools and it is taught to students in Form Four who are 16 years old. Based on Malaysia Curriculum Development Centre (CDC, 2005), BC is discussed under 'Maintenance and Continuity of Life' as in (Appendix 1) but for this article purposes, discussion is limited only to subtopics body coordination, human nervous system, nervous coordination, human brain, hormonal coordination and coordination between the nervous system and the endocrine system. According to Yin (2003) and Stake (1995), placing the boundaries on study can prevent the data explosion from occurring.

Some studies also suggested that the $\mathrm{BC}$ as motor coordination plays an important role in the social, emotional and activities related to academics (Wijnroks \& van Veldhoven, 2003).

Location of study in Malaysia Sabah can be traced via Maps Google Earth (Appendix 2).

\subsection{Aim of Study}

The aim of this paper was to explore students' understanding of BC.

\subsection{Research Question}

What is the level of students' understanding of body coordination topics?

\section{Literature Review}

A few scholars regard misconception and Alternative Framework (AF) as the same thing. There is much discussion in the literature of the notions of misconceptions, naïve conceptions and alternative conceptions, and many researchers have a preference for one term over another. Sneider and Ohadi (1998; Read, 2004) wrote that "[m]any researchers object to the term 'misconception' because, from the student's viewpoint, the ideas expressed are logical. 'Preconceptions', naïve theories', and 'alternative frameworks' have been proposed as better terms for students' personal views that are at odds with modern scientific theories." but Davy \& Jomini ( 2013) regard these concepts as different. We examined that misconception is mis about any science concepts but AF arises from more than one misconcepts. Huge collection of misconcepts form the AF. AF term was first used by Driver and Easley (1978; 
Nussbaum and Novick, 1982). Davy (2012) suggested the concluded that AF all other mistakes concept can be simplified and categorized into two levels as shown in Table 1.

Table 1. Types of mistakes of AF and their level

\begin{tabular}{lll}
\hline Concept Mistakes & Level \\
\hline alternative conception, concept difficulty, misconceptions, naive belief, & 1 \\
personal conception, existing knowledge, student perception, student & \\
preconception, student representatives, student view, student view. & \\
alternative framework, concept framework, alternative multi explanation. & 2 \\
\hline
\end{tabular}

Source: Davy (2012)

Studies of BC involving the entire limb of the human body showed that the human body is a fascinating subject for discussion by the expertise of each individual scholars.

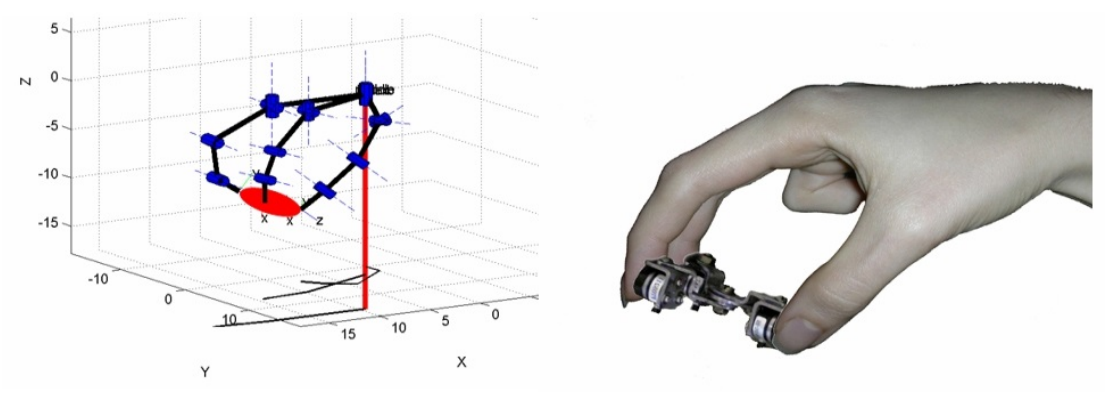

Figure 1. Kinematics of Human Hand

Source: (Siena di University, ItaliU.O. \& Milan U.O, 2004)

Study of (Pozzo, Stapley \& Papaxanthis, 2002) found that an increase in body posture barriers significantly affect the trajectory (movement) hand and arm. The independent variable equilibrium and kinematic trajectory end points analyzed during the reach things done. Previous studies (Pozzo et al., 1998) on the grip and take up (Kerlirzin et al., 1999) shows a correlation between BC in the balance of the body and curved hand movements.

According to Mustafa (2007), the level of understanding of students is classified into three categories as in Table 2.

Table 2. Category of Students understanding

\begin{tabular}{|c|c|c|}
\hline Category & Description & Example \\
\hline Category 1 & evidence of student & 'I do not know ..' \\
\hline Category 2 & students' responses showed AF / misconceptions & 'glands located at the foot' \\
\hline Category 3 & students have a full understanding & $\begin{array}{l}\text { 'the example of } \\
\text { drug is cocaine' }\end{array}$ \\
\hline
\end{tabular}

Source: Mustapa (2007)

$\mathrm{BC}$ studies were made in the field of aviation (aviation). For example, in situation of gravity during a parabolic flight (0 gravity, g) and normal gravity conditions ( $1 \mathrm{~g})$ which focuses on how the central nervous system is maintained in parts of the body being studied (Jerome, Paul \& Thierry, 2005). BC in parabolic flights applied in flight simulation short-term scientific and technology to investigate microgravity and reduction, instrumental test before into space, verifies the operation and experimental procedures and to train astronauts for future flights. Figure 2 shows the lab parabolic flights simulation and Figure 3 shows the degree of stability of height versus time during parabolic flights.

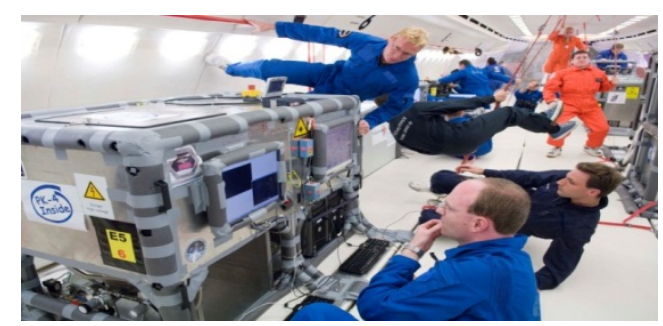

Figure 2. Lab Parabolic Simulation

Source: www.esa.int/spaceinimages (2008). 


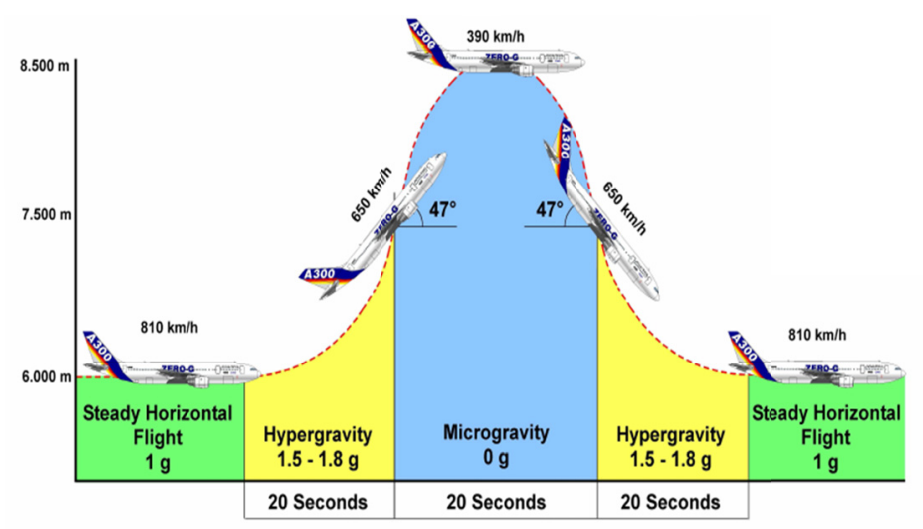

Figure 3. Parabolic Flight

Source: Christoph, (2011)

\section{Method and Sampling}

We administered the Body Coordination Two Tier Concept Test (BCTTCT) to examine and detect the student understanding, include the related science concept and any AF within students because Driver and Easley (1978) report that an alternative framework tools is appropriate to describe the framework of student opinion of their own autonomy to interpret a natural phenomenon. First version of BCTTCT consists 20 questions 2 level (two-tier). Two tier question were pioneered by Haslam and Treagust (1987) to detect misconception among students and then we analysed them based on types of understanding level by Mustafa (2007). We sought the teacher in the school to identify the students based on their performance.

Purposive sampling was used in our study. After discussion and explanation in supervision process, we suggested that 14 questions only should be included in BCTTCT. Sample of BCTTCT, see Appendix 3. Second phase is initial survey to the real site. We removed the six question from fifteen to twenty because our study will concentrate and relate to $\mathrm{BC}$ topic only. We considered this method appropriate to collect information from students that is useful to review what was there even in the students, contact, environment, school or interview is capable of delivering data to the researchers.

\section{Validity and Reliability}

To validate the BCTTCT we administered of pilot study to 54 students in other school in Malaysia. All students marks was 389. Difficulty level subjective questionwas 0.55. Based on Anthony (2000), BCTTCT is medium difficulty and ready to run in field. BCTTCC was checked by two university professors and one associate professor to increase the validity. The grammar was checked and verified by Dewan Bahasa dan Pustaka (DBP). DBP is solely Malaysian government to empowerment the credibility the language in Malaysia.

\section{Data Collection}

Data was collected for two weeks. First day, in grouping session, we introduced and explained to respondents why they are selected in this study then students answer the BCTTCT. Second day, 6 selected students three male and three female aged sixteen years old from one school continued with in depth interview session.

In this study we preferred the phenomenology design to facilitate exploration of a multi concept and experience of AF in BC topic within its context using a variety of data sources and strategy. Research Paradigm employed here is pragmatism. We considered used the pragmatism because mostly studies focused on qualitative research, but in certain circumstances as in the testing and evaluation of data, numbering aspect is indispensable.

\section{Findings}

Student marking can be seen in Table 3, descriptive analyse, mean student 1.71 and average 1.62. After evaluated the students' answer, we detected and categorized all students answer as followed in Table 4. 
Table 3. Student Marks

\begin{tabular}{|c|c|c|c|c|c|c|}
\hline Students & Students 1 & Student 2 & Student 3 & Student 4 & Student 5 & Student 6 \\
\hline & (S1) & (S2) & (S3) & (S4) & (S5) & (S6) \\
\hline Question & & & & & & \\
\hline 1 & $\sqrt{ }$ & & $\sqrt{ }$ & & & $\sqrt{ }$ \\
\hline 2 & $\sqrt{ }$ & $\sqrt{ }$ & & & $\sqrt{ }$ & \\
\hline 3 & & & $\sqrt{ }$ & & & \\
\hline 4 & & & & $\sqrt{ }$ & & \\
\hline 5 & & $\sqrt{ }$ & $\sqrt{ }$ & $\sqrt{ }$ & & \\
\hline 6 & $\sqrt{ }$ & $\sqrt{ }$ & $\sqrt{ }$ & & $\sqrt{ }$ & \\
\hline 7 & & $\sqrt{ }$ & & $\sqrt{ }$ & $\sqrt{ }$ & \\
\hline 8 & & & & & & $\sqrt{ }$ \\
\hline 9 & & & & & & $\sqrt{ }$ \\
\hline 10 & $\sqrt{ }$ & $\sqrt{ }$ & & & & \\
\hline 11 & $\sqrt{ }$ & & $\sqrt{ }$ & & $\sqrt{ }$ & \\
\hline 12 & & $\sqrt{ }$ & & $\sqrt{ }$ & & \\
\hline 13 & & & & $\sqrt{ }$ & & \\
\hline 14 & & $\sqrt{ }$ & $\sqrt{ }$ & $\sqrt{ }$ & & $\sqrt{ }$ \\
\hline
\end{tabular}

Table 4.

\begin{tabular}{lll}
\hline Category & Description & Students \\
\hline Category 1 & responses showed no evidence of student understanding & S1: Q3, Q7, Q8, Q10, Q11, \\
& & Q12. \\
& & S2: Q1, Q4, Q9, Q13. \\
& S4: Q1, Q2, Q6, Q8, Q10, \\
& Q11. \\
& S5: Q3, Q4, Q5, Q8, Q12. \\
& S6: Q2, Q3, Q4, Q5, Q7, Q10, \\
Category 2 & Q12, Q13. \\
& & S1: Q4, Q5, Q9. \\
& S2: Q3, Q4, Q11. \\
& S3: Q2, Q8, Q9. \\
Category 3 & S4: Q3, Q9. \\
\hline
\end{tabular}

\section{Discussions}

Student marking can be seen in Table 3, descriptive analyse, mean student 1.71 and average 1.62. After evaluating the students' answer, we detected and categorized all students answer as indicated in Table 4. 40.96 percent student answered we categorized 1, 20.48 percent student answered category 2 and 38.55 student answered. Finding shows that students in interior of Malaysia still have the AF and misconception about BC. The data confirm the view that children do not come to primary science lessons as a 'tabula rasa' but come with rich knowledge about their physical world based on their everyday experience, as Vosniadou and Ionnades (1999) proposed. There are several ways that students develop conceptions, AF and misconceptions. Some of the sources of misconceptions include everyday observations, religious or mythical teachings, science teaching that does not adequately challenge students' misconceptions, and vernacular misconceptions (Smolleck \& Hershberger, 2011).

Terusan Sugut Secondary School are fewer secondary schools in Malaysia situated in the island. Next visit to these school, we will conduct the full research with other school. This preliminary data will provide the important data to researcher before going to site again for collecting data from students and their surroundings.

\section{Conclusion}

We should listen what student says. Don't blame students when their answer is wrong or bad. Teachers should be creative, and employ diverse methods of teaching and learning in the classroom to engage and attract students.

Because of this research only progress report, that why this study tends to discuss more generally here. This progress may suite for research context only, maybe not suitable to apply in other place. Researcher still ongoing process to complete the findings include the other school again in Malaysia.

\section{Acknowledgments}

1. This research was supported by Yayasan Sabah, Malaysia or Sabah Foundation, 2014 under Rural

Development Research And Ethnography grants, R\&D Section. 


\section{References}

Anthony, J. N. (2000). Educational Assessment of Student: Third Edition.

Christoph, (2011). http://siliconroadpartners.com/author/christoph/. (Retrieved by 24th February 2014).

Curriculum Development Centre. (2005). Integrated Curriculum for Secondary School. Science form 4. Ministry of Education Malaysia.

Davy, S. (2012). Alternative Framework, Attitudes towards Science and Problem Learning: A Pilot Study. International Organization of Scientific Research. 2( 2), 28-41.

Davy, S., \& Jominin, G. (2013). Misconception or Alternative Framework: Which One? Macrotheme International Conference Paris Business and Social Science, 20-21.

Driver, R., \& Easley, J. (1978). Pupils and paradigms: A review of literature related to concept development in adolescent science students. Studies in Science Education, 5, 61-84. http://dx.doi.org/10.1080/03057267808559857.

Haslam, F., \& Treagust, D. F. (1987). Diagnosing secondary students' misconceptions of photosynthesis and respiration in plants using a two-tier multiple choice instrument. Journal of Biology Education. 21 (3), 203-211.

http://www.esa.int/spaceinimages/Images/2008/11/Day2ofthe49thESAParabolicFlightCampaignThePK4plasmacry stalexperimentbeingpreparedforflighttotheISS. (Retrieved by 24hb February 2014).

Jerome, P., P, S., \& Thierry, P. (2005). Human whole-body reaching in normal gravity and microgravity reveals a strong temporal coordination between postural and focal task components. Experimental Brain Research, 165(1), 84-96. http://dx.doi.org/10.1007/s00221-005-2283-0

Kerlirzin, Y., Pozzo, T., Dietrich, G., \& Vieilledent, S. (1999). Effects of kinematics constraints on hand trajectory during whole-body lifting tasks. Neurosci Lett, 277, 41-44. http://dx.doi.org/10.1016/ S0304-3940(99)00843-5.

Sabitha, M., (2005). KAEDAH PENYELIDIKAN SAINS SOSIAL. Prentice Hall Pearson Malaysia Sdn. Bhd.

Mustafa, C. (2007). Alternative Views Of The Solar System Among Turkish Students. Review of Education. 53, 39-53.

Nussbaum, J., \& Novick, S., (1982). Alternative Framework, Conceptual Conflict And Accomodation: Toward A Principled Teaching Strategy. Elsevier Scientific Publishing Company, Amsterdam. Instructional Science, 183-200.

Pamela, B., \& Susan, J. (2009). Qualitative Case Study Methodology: Study Design and Implementation for Novice Researchers.

Pozzo, T., McIntyre, J., Cheron, G., \& Papaxanthis, C. (1998) Hand trajectory formation during whole body reaching movements in man. Neurosci Lett , 240, 159-162. http://dx.doi.org/10.1016/S0304-3940(97)00943-9.

Pozzo, T., Stapley, P. J., \& Papaxanthis, C. (2002). The coordination between equilibrium and focal components of whole body pointing movements in man. Experimental Brain Research, 144, 343-350. http://dx.doi.org/10.1007/s00221-002-1052-6 PMid:12021816.

Read, J. R. (2004). Children's Misconceptions and Conceptual Change in Science Education. http://acell.chem.usyd.edu.au/Conceptual-Change.cfm (Retrieved 20th January 2015).

Siena, U. O., \& Milan, U. O. (2004). http://www-lar.deis.unibo.it/aida/B-mod-unisi-en.htm.

Smolleck, L., \& Hershberger, V. (2011). Playing with Science: An Investigation of Young Children's Science Conceptions and Misconceptions. Current Issues in Education, 14(1). http://cie.asu.edu/ojs/index.php/cieatasu/article/view/.

Stake, R. E. (1995). The art of case study research. Thousand Oaks, CA: Sage.

Vosniadou, S., \& Ionnides, C. (1998) From conceptual development to science education: a psychological point of view. International Journal of Science Education, 20(10), 1213-1230. http://dx.doi.org/10.1080/0950069980201004

Wijnroks, L., \& Van Veldhoven, N. (2003). Individual differences in postural control and cognitive development in preterm infants. Infant Behavior and Development, 26(1), 14-26. http://dx.doi.org/10.1016/S0163-6383(02)00166-2.

Yin, R. K. (2003). Case Study Research: Design and Methods (Third Edition). Sage Publications.

Zurida, I., Sharifah, N., \& Mohd, A. S. (2006). Kaedah Mengajar Sains. Bentong: PTS Profesional Sdn. Bhd. 


\section{Appendices:}

Appendix 1

Source: CDC (2005)

\begin{tabular}{ll}
\hline No. & Title: \\
\hline & Body Coordination \\
1 & Body Coordination \\
2 & Human Nervous System \\
3 & Nervous Coordination \\
4 & Proprioceptors \\
5 & The Human Brain \\
6 & Hormonal Coordination \\
7 & Coordination Between the Nervous System and \\
& the Endocrine System \\
\hline
\end{tabular}

Appendix 2

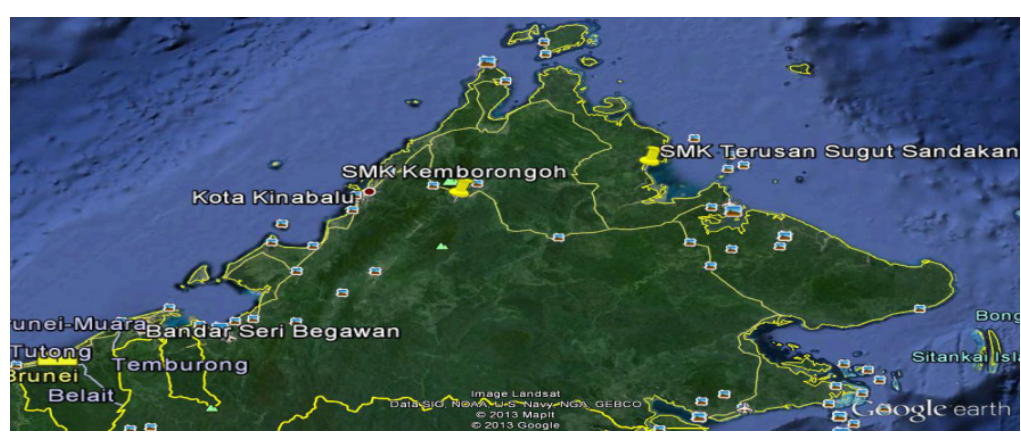

\section{Appendix 3}

\section{Body Coordination Two Tier Concept Test}

Test item 1: Mark [/] two types of coordination of the human body.

$$
\begin{aligned}
& \text { i) } \square \text { Coordination Nervous. } \\
& \text { ii } \square \text { he Endocrine System. } \\
& \text { iii) } \square \text { oordination Chemistry. }
\end{aligned}
$$

\section{Because:}
a) Less organ systems work together to make the response.
b) Serve as a centre of reflex action.
c) organ system can work at the appropriate time and rate for make the response.
d) Is the path of impulses between the brain and peripheral nerves.
e) Control of voluntary actions in human behaviour.
f) Other answers:

Test item 2: What is the importance of coordination of the body?
a) Detection of the stimulus.
b) Perform response.
c) Coordinate the activities of the body.
d) Coordinate and harmonize the body response.

Because:

Test item 3: Central nervous system is the central receiver and the interpretation of nerve impulses from the receptors and sense organs.

$$
\text { (Please tick (/) in one box below) }
$$

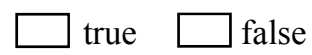




\section{Because:}

a) Sent to the brain for interpretation.

b) Submitted to the parts of the body for storage.

c) The impulse which has been interpreted to be sent to the organ concerned to perform involuntary response.

d) Autonomic nerve stretches from the blood vessels, organs and glands in the body to the spinal cord.

e) The impulse which has been interpreted by the brain will be sent to a particular organ to carry out the response.

g) Other answers:

Test item 4: Cranial nerve and spinal cord are two groups that make up the spinal peripheral nerves.

(Please tick (/) in one box below)

$\square$ true $\square$ false

Where is cranial nerve in the human body?
a) In the lymph
b) In the brain
c) In the heart
d) In the stomach
e) At the foot
f) In the arms
g) Other answers:

\section{Test item 5 and 6 is based on Figure 1}

Test item 5: Figure 1 shows a crossing impulses in the nervous system to a stimulus.

Effectors

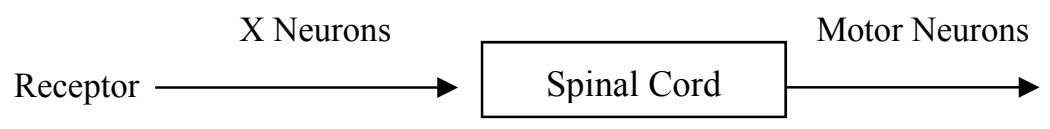

Figure 1

Name the X neuron Figure 1.

Neurons X:

\section{Because:}

a) Route CNS X is to the spinal cord to the brain and back to the effector for action.

b) X Neurons carry impulses to the brain to be interpreted without a nerve cord.

c) Neurons carry impulses directly to $X$ without going through the spinal cord synapse.

d) Carry impulses from the CNS X receptor to the spinal cord.

e) Neurons carry impulses from $X$ to the spinal cord motor neurons.

f) Other answers:

Test item 6: Figure 1 shows a crossing impulses in the nervous system to stimulus.

Effectors

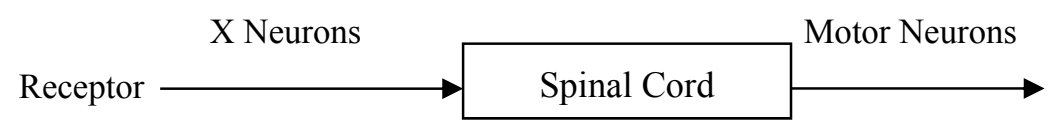


Figure 1

Name the action in Figure 1

(Please tick (/) in one box below)

$\square \quad$ Refl $\square$ action Controlled Action

\section{Because:}

Test item 7: Mark [/] two types of coordination of the human body.

i) $\square$ rdination Nervous.

ii $\square$ e Endocrine System.

iii) brdination Chemistry.

\section{Because:}

a) Less organ systems work together to make the response.

b) Serve as a centre of reflex action.

c) Organ system can work at the appropriate time and rate for make the response.

d) Is the path of impulses between the brain and peripheral nerves.

e) Control of voluntary actions in human behaviour.

f) Other answers:

\section{Test item 8:}

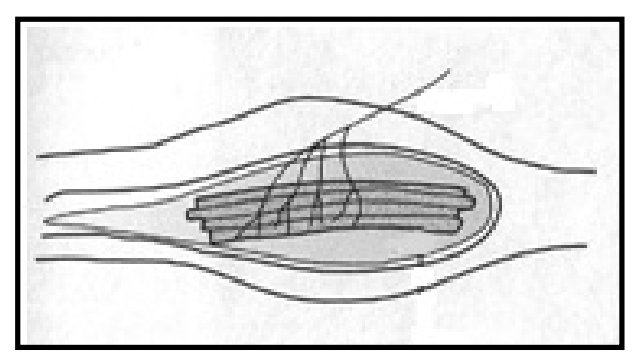

Figure 2

In your opinion, what is the name of biology in Figure 2?

Because:

Test item 9:

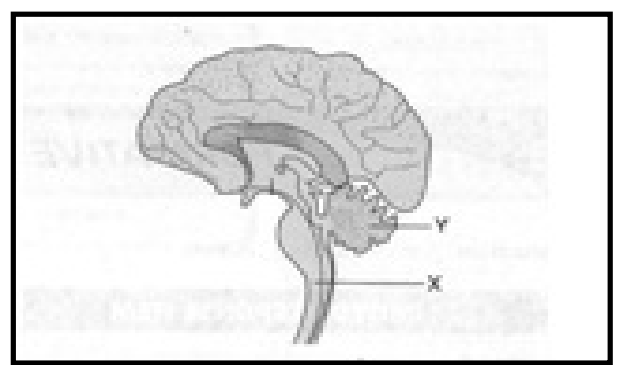

Figure 3

The part labelled $\mathrm{X}$ and $\mathrm{Y}$ in Figure 3 is

I) Cerebral

II) Medulla oblongata 
III) The Cerebellum
A) 1 and II.
B) II and III only.
C) III only.
D) I and III.

\section{Because:}

a) $\mathrm{X}$ is used to control memory, thought, position, and voluntary actions, $\mathrm{Y}$ is used to control movement, balance and posture.

b) $\mathrm{X}$ is used to control memory, thought, position, and voluntary actions, $\mathrm{Y}$ is used to control involuntary actions.

c) $\mathrm{X}$ is used to control movement, balance and posture, $\mathrm{Y}$ is used to control the memory.

d) $\mathrm{X}$ is used to control involuntary actions and $\mathrm{Y}$ functions for control movement, balance and posture.

e) $\mathrm{X}$ is used to control movement, balance and posture, $\mathrm{Y}$ is used to control involuntary actions. control.

f) $\mathrm{X}$ is used to control movement, balance and posture, and $\mathrm{Y}$ is used to control memory, thought and action

g) Other answers:

Test item 10: Write the part of the brain that controls involuntary actions and an example of involuntary action activities in Figure 4.

Foreign Regulatory Actions

\begin{tabular}{l}
\hline Foreign Regulatory Actions \\
\hline Part Brain \\
\hline An Example of Activity \\
\hline
\end{tabular}

\section{Figure 4}

Test item 11: The biology in Figure 5 below is called pancreas.

(Please tick (/) in one box below)
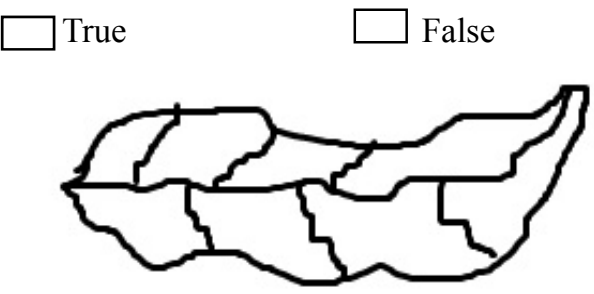

Figure 5

\section{Because:}

a) Functional secretes the hormone adrenaline.

b) Functional secrete hydrochloric acid is weak.

c) Functional secretes the hormone insulin to control the content salt in the body.

d) Functional secretes gastric juice

e) Functional secretes gastric juice in the juice works to kill microorganisms in food.

f) Serve secretes the hormone insulin to control the content level glucose in the body.

g) Other answers:. 
Test item 12: The biology in Figure 6 below is called pancreas.

(Please tick (/) in one box below)

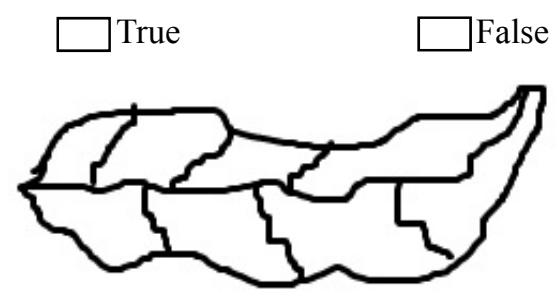

Figure 6

\section{Because:}
a) Its located behind the heart.
b) The position is located below and behind the stomach.
c) The position is located below and in front of the stomach.
d) The position is located above and behind the stomach.
e) The position is located above and in front of the stomach.
f) Other answers:

Test item 13: The $X$ in Figure 7 shows the position of the thyroid glands.

(Please tick (/) in one box below)

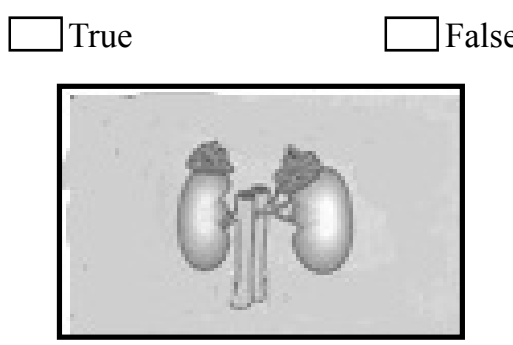

Figure 7

\section{Because:}

a) Produce hormones to control the growth process.

b) Secrete adrenaline to increase the pulse, respiration, blood pressure and glucose levels during an emergency.

c) Creating a control testoran men, including the production of sperm.

d) To produce oestrogen and progesterone that regulate female organs, including the menstrual cycle.

e) Other answers:

Test Item 14: Figure 8 shows a picture of a balance between Nerves coordination and Hormones coordination.

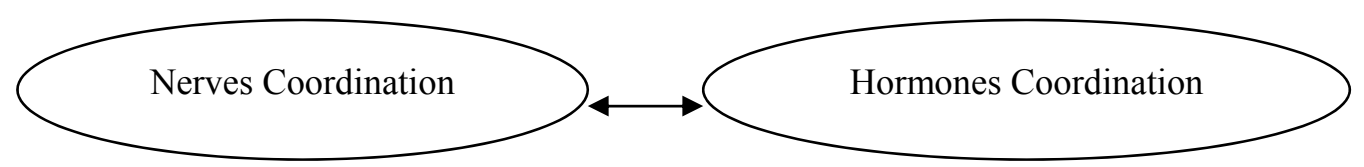

Figure 8 
Give one similarity and one difference between nerve Coordination and Hormone Coordination.

$$
\text { Similarity }
$$

Differences

\section{(cc) $\mathrm{EY}$}

This work is licensed under a Creative Commons Attribution 3.0 License. 